\title{
Full color laser television
}

\section{Laser Vision Technologies \\ 16630 SW Shaw Suite D \\ Aloha, Or. 97007}

\section{Abstract}

Full color laser television has been demonstrated using a combination of three solid state lasers with average power per laser of about $15 \mathrm{mw}$. The picture was illuminated with wavelengths of red $635 \mathrm{~nm}$, green $532 \mathrm{~nm}$ and blue $473 \mathrm{~nm}$ these three wavelengths produce a color triangle exceeding TV phosphors and movie film.

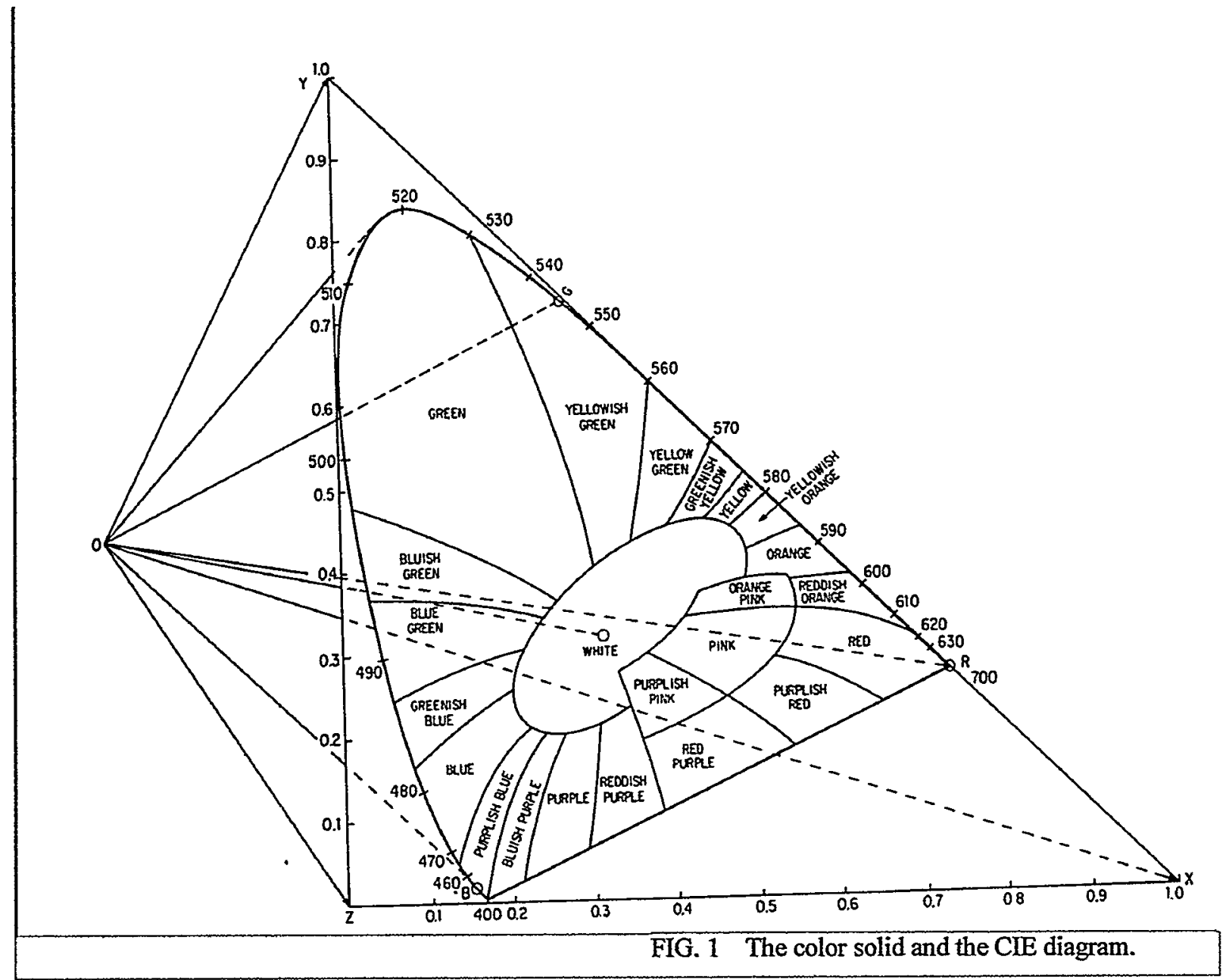




\section{DISCLAIMER}

This report was prepared as an account of work sponsored by an agency of the United States Government. Neither the United States Government nor any agency thereof, nor any of their employees, make any warranty, express or implied, or assumes any legal liability or responsibility for the accuracy, completeness, or usefulness of any information, apparatus, product, or process disclosed, or represents that its use would not infringe privately owned rights. Reference herein to any specific commercial product, process, or service by trade name, trademark, manufacturer, or otherwise does not necessarily constitute or imply its endorsement, recommendation, or favoring by the United States Government or any agency thereof. The views and opinions of authors expressed herein do not necessarily state or reflect those of the United States Government or any agency thereof. 


\section{DISCLAIMER}

\section{Portions of this document may be illegible in electronic image products. Images are produced from the best available original document.}


The laser television system is based on the assumption that a monochromatic coherent visible laser beam can be manipulated to produce a visual image on a screen.

Laser beam manipulation follows the elements prescribed by the video signal architecture. Acousto-optic modulators (AOM) using Bragg deflection encode the laser beam, in such a way that the true visual image when scanned would produce a replica image of the electronic video signal. Scanning the modulated laser beam is done with a polygon (horizontal) and a galvanometer (vertical).

Thus, a laser television is a process of manipulating a laser beam in such away that it produces a true visual image.

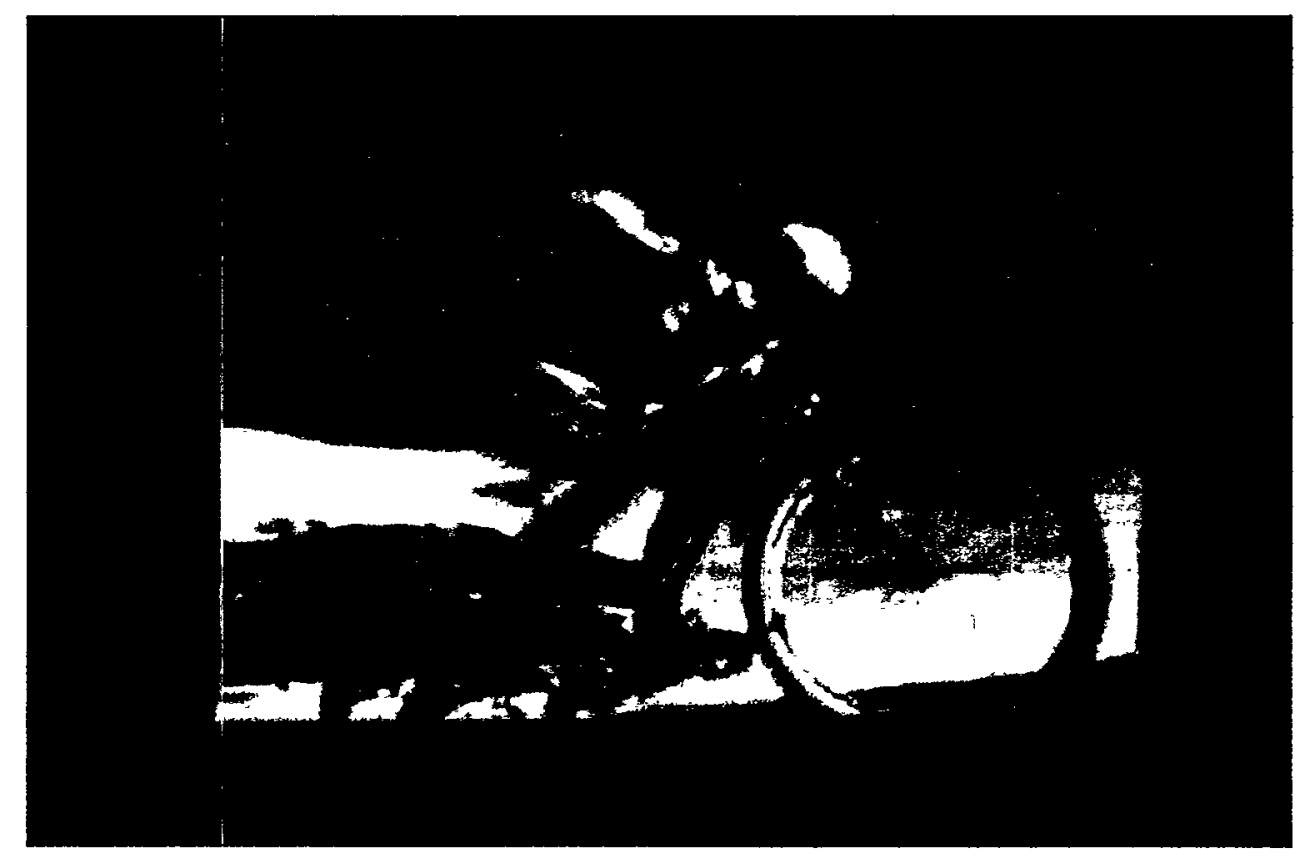

\section{Introduction}

A laser television paints an image by scanning a beam of laser light directly on the projection screen. The image on the screen is seen because of the concept of visual persistence in the eye. Laser displays inherently posses many features that produce a high quality visual display. Several of these elements are fully saturated colors, and high-resolution contrast. High color saturation is possible because each color is a single wavelength of light, and all three colors added together produce a very bright white light. High picture resolution and contrast 
are a function of AOM bandwidth and laser light propagation characteristics. The features of high color saturation and high picture resolution have been a driving force over the years for labs to try and build a laser television. Historically, laser projection displays have used Argonion lasers for green and blue colors and either a Krypton laser or an Argon-ion pumped dye laser for red. These early laser projectors were somewhat successful in showing the potential of laser projection but these lasers were inefficient, and to obtain reasonable output power, kilowatts of input power were necessary. So, with the progression of solid state technology our goal was to build a laser television using only solid state lasers. Ref 4

Clearly the benefits of smaller solid state lasers makes the potential for laser television a reality in the near future.

\section{The Laser Display System}

\section{Theory of operation}

The model used to develop the laser TV very closely matches a modern day television. In current televisions the cathode ray tube (CRT) is the source of illuminated light. The CRT functions by scanning electrons across and down a screen having pixels of red, green, and blue phosphors. The scanning process produces a full color image on the face of the CRT, which is then viewed by the viewer.
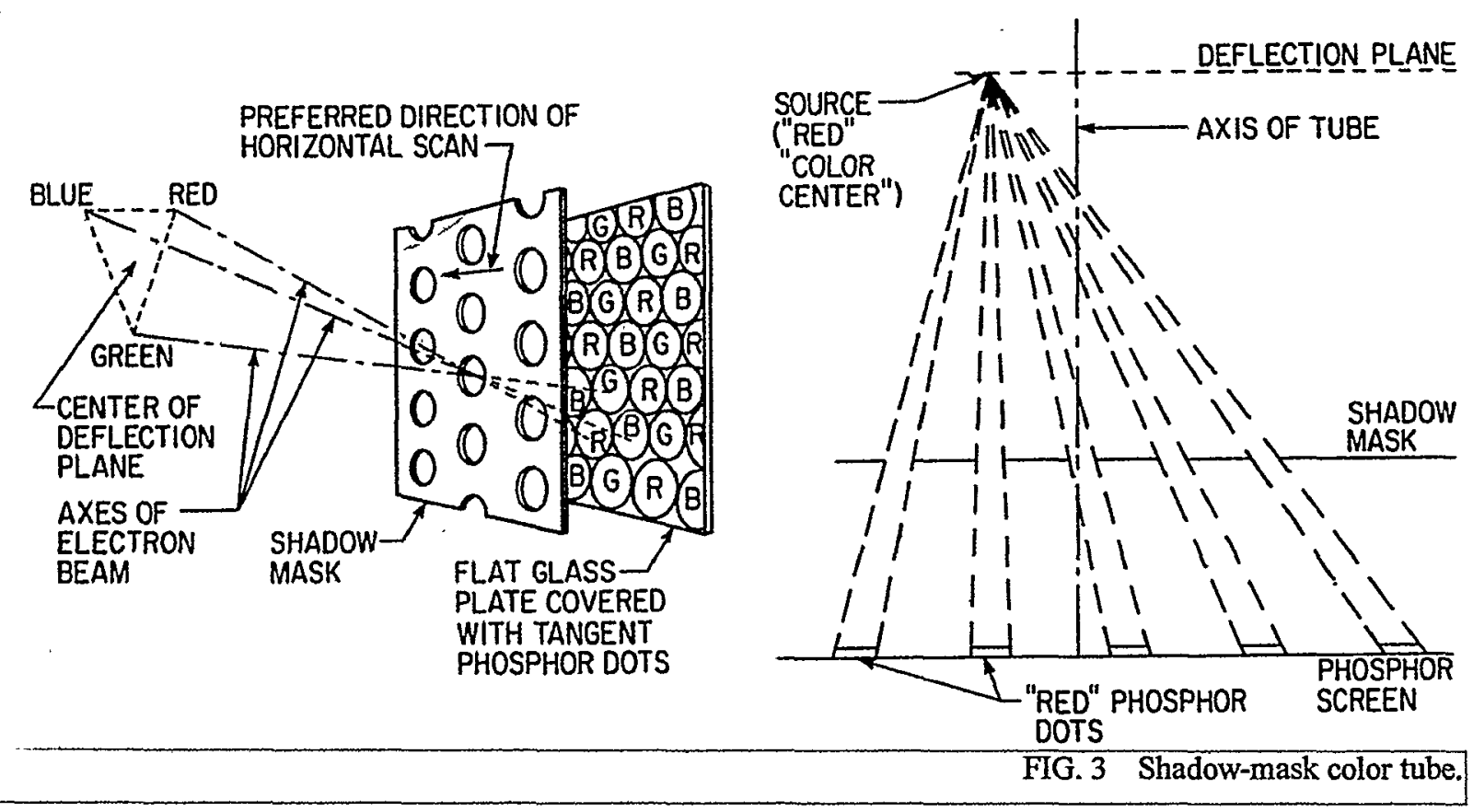
The laser TV uses similar elements to the CRT television, horizontal scanning, in the form of a spinning mirror or polygon, vertical scanning, in the form of a galvanometer or oscillating mirror, and individual red, green and blue pixels combined to produce a full color picture image.

The primary motivation to use lasers for display of video comes from the huge color triangle that laser light can reproduce. No other light sources can reproduce an image with the same amount of hue and saturation. This large color triangle reproduced by laser light is a function of the fact that phosphors in CRT's and pigments in film cannot produce wavelengths, as broad as those represented by $435 \mathrm{~nm}$ red, $473 \mathrm{~nm}$ blue and $532 \mathrm{~nm}$ green. Also, laser light is monochromatic a single wavelength for that color. This single wavelength when projected and viewed produces extremely deep, rich colors only matched in nature. (Ref1)

\section{Light source-lasers.}

The name solid state laser refers to lasers that are primarily either a laser diode or a laser diode and some crystal combination. Coherent and monochromatic light is produced in a laser cavity. There are two different types of laser cavity design, internal and external, and each one of these designs produces a wide range of output light characteristics. A laser cavity can be manufactured into a small piece of semiconductor material called a laser diode. Laser diodes can produce output light in a wide range of wavelengths for many different applications. Few laser diodes however, produce visible wavelengths that can be used for a laser TV, and the ones that do, are in the red range $635 \mathrm{~nm}$ to $660 \mathrm{~nm}$.

Solid state lasers are either individual laser diodes or laser diodes used in combination with specific gain and lasing crystals. Lasers that use laser diodes in conjunction with gain and lasing crystals are called diode pumped lasers. Diode pumped lasers are able to produce output wavelengths more varied than what can be manufactured as direct laser diodes.

Microlasers are one type of diode pumped laser. These lasers have the gain medium and lasing crystal all manufactured together in a very small package. The pump laser diode energy is focused into the crystal assembly with an output wavelength different than the pump diode. These lasers use an internal laser cavity design called intracavity doubled. Intracavity doubled lasers come in small packages, which is desirable, however, they produce a beam with a lot of chaotic noise. Noise free solid state diode pumped lasers are very expensive at this current time. (Ref, 2) 


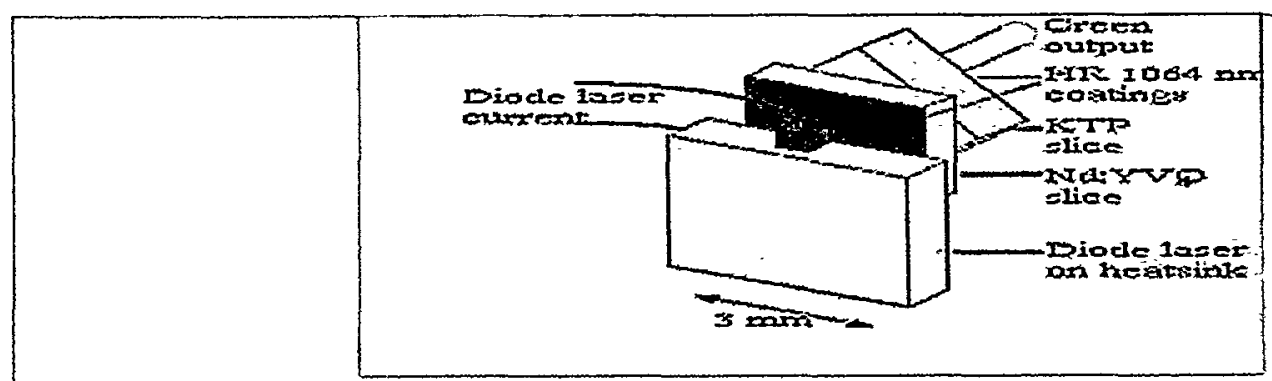

FIG. 4Microlaser

The solid state lasers we used were a direct red laser diode at $635 \mathrm{~nm}$ and $15 \mathrm{~mW}, 473 \mathrm{~nm}$ diode pumped blue about $20 \mathrm{~mW}$, and a $532 \mathrm{~nm}$ diode pumped green at about $40 \mathrm{~mW}$.

The diode pumped lasers we used for the prototype had noise associated with their output beams. Noise in the laser beam resulted in a video picture that had a snowy appearance. The issue of noise in the laser beam also made it more difficult to propagate the laser beam and achieve high resolution.

The issue of noise in the laser beam becomes more visible in the video picture as more laser power is needed to produce a bigger and brighter picture. (Ref. 3)

\section{Video modulation of the lasers}

The most common approach to laser beam modulation is acousto-optic. When light is directed through an optical element the output light is bent, like in a prism, also sound waves can be made to travel through optical elements. When a beam of light passes through a crystal that has sound waves traveling through it, the refracted light will duplicate the pattern of the sound wave. AOM's produce a sound wave in a $\mathrm{TeO} 2$ crystal and this sound wave is a transform of the video signal. So, as the laser beam passes through the crystal, sound waves refract the laser light or modulate it to match a transform of the electrical video signal. This modulated light is then scanned to produce the visible picture. 


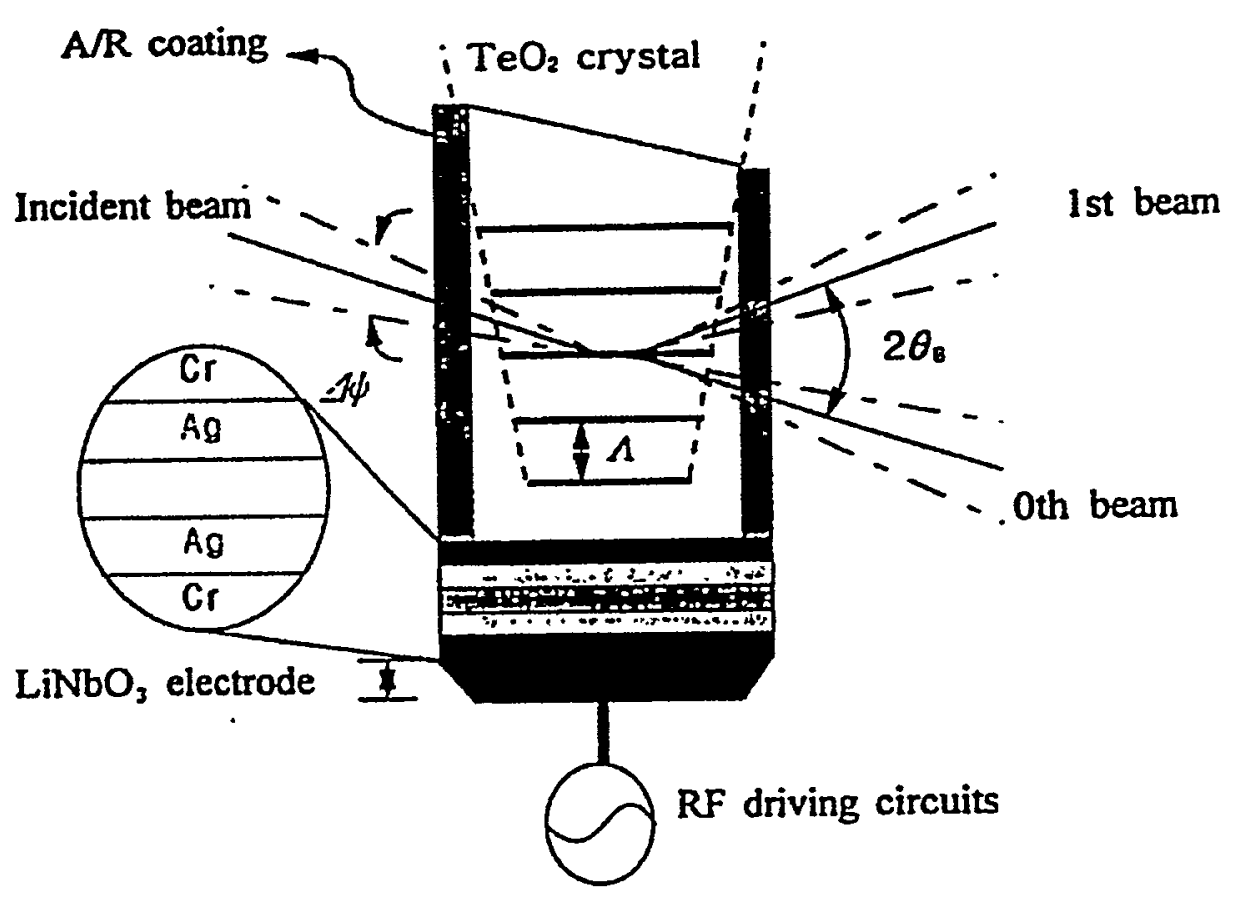

Schematic of the acousto-optic modulator

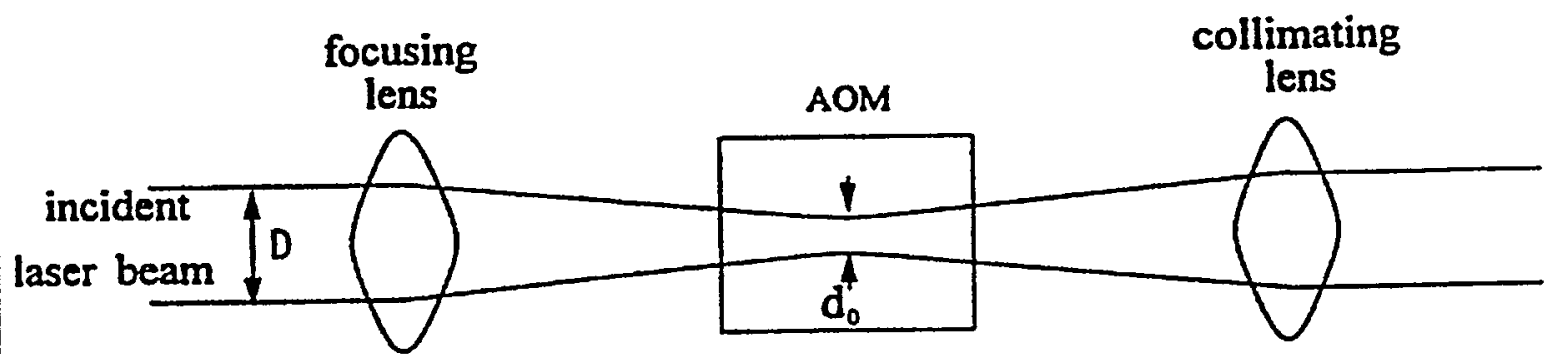

Schematic of the laser beam tracing in acousto-optic modulator

(a)

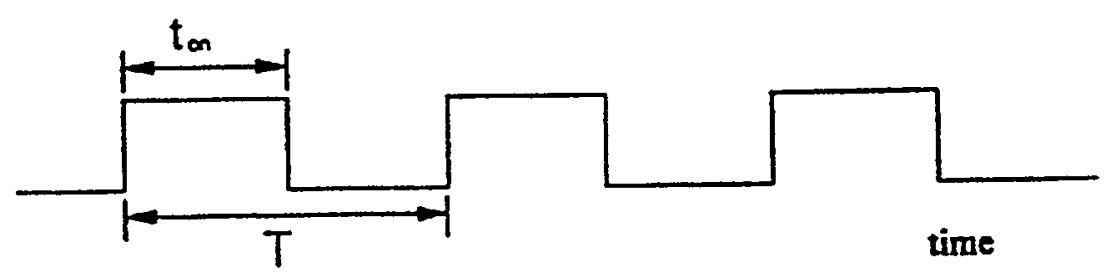

(b)

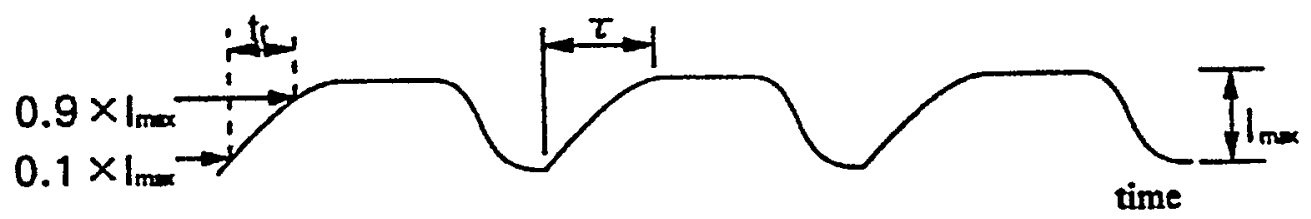

(a) Typical sequence for input video signal

(b) Modulated AO drive signal 
Even though AOM's can modulate video, manufactures of AOM's do not have specific specifications as to expected results for this application. In addition, the literature we found describing video modulation with AOM's was inaccurate or just wrong. The performance of an $A O M$ is based on many factors and here are some we observed.

A gaussian beam is the ideal beam shape for laser application because it can be focused and collimated well. A gaussian beam will give a more proportional modulated output beam thus better picture resolution. Even if the beam is gaussian going into the AOM it may not be coming out. The crystalline structure of the $\mathrm{TeO} 2$ is such that imperfections in the crystals will cause some output beam distortions. These imperfections in the crystal can cause the AOM's efficiency to be lowered.

AOM efficiency is a function of crystal quality and size, laser beam wavelength, profile and size. These are very important elements about AOM crystals and are not part of AOM manufacture's application specifications.

The principle used to display video with lasers is based on the manipulation of a laser beam at the pixel level of information. AOM's can regulate the percentage of light needed at each pixel to produce an exact duplication of the video signal and hopefully the original picture. A very high-resolution picture can be achieved with this type of modulation because the bandwidth of AOM's exceeds current video standards so they make an excellent video modulator. Acousto-optic modulation works very well, but the cost of $\mathrm{TeO} 2$ (the best material for this type for modulation), it's availability, and the high frequency RF driver, make AOM expensive for mass production. Also the AOM driver needed a lot of power which in turn created a need for a lot of heat sinking.

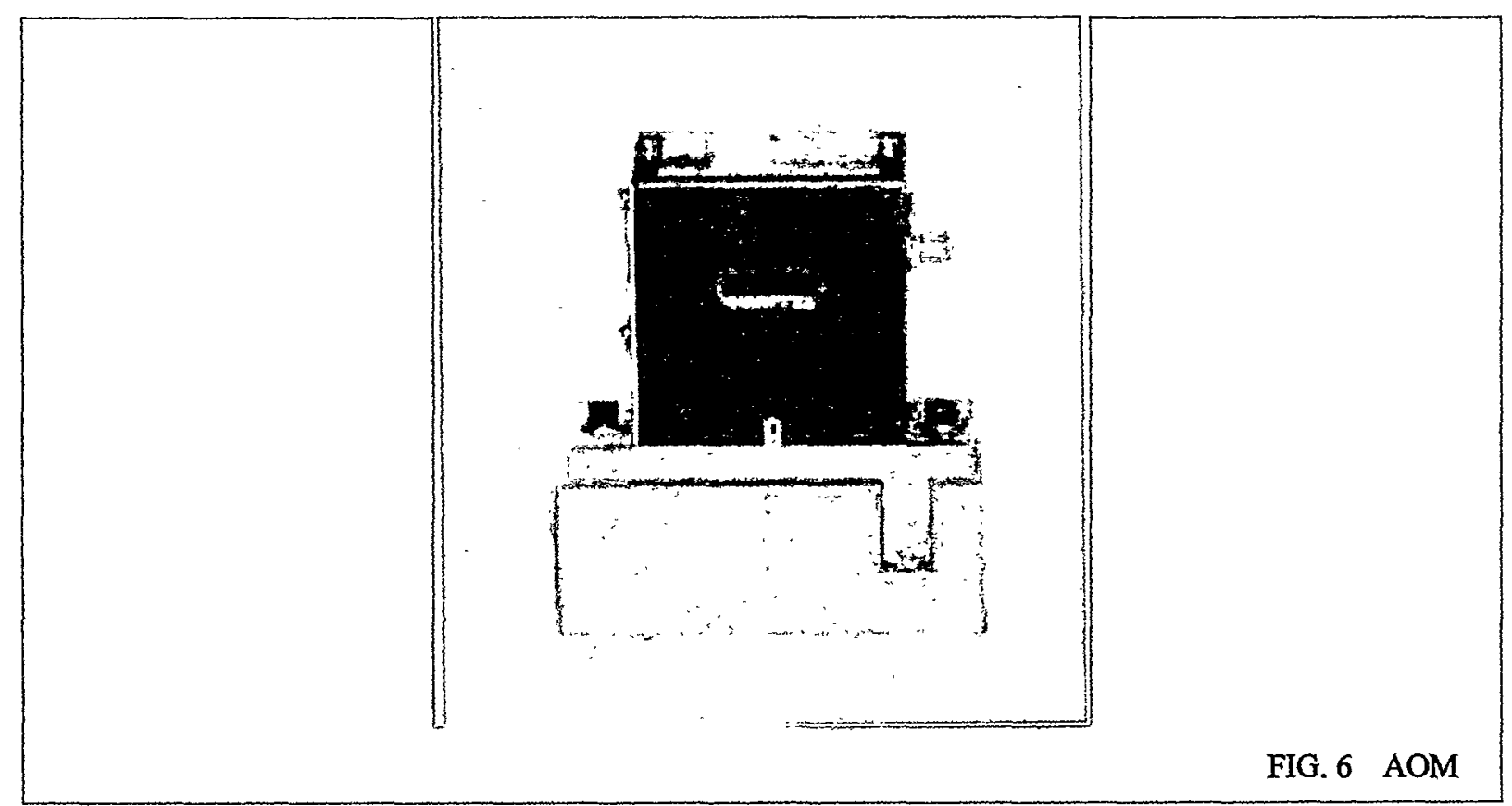




\section{Optical Design}

The goal of the optical design was to present the best picture on the screen, our prototype design was very inefficient, thus we lost a lot of light before it got to the screen.

The optical design was made up of two separate optical systems, one system dealt with preparing the beam for the scanning system and the other system taking the modulated beam through the process of getting it to the screen.

Understanding the characteristics of each individual laser beam was important. Focusing and collimating the laser beam is a key function to good beam propagation. Propagation of the laser beam is the key to picture resolution, having a small beam spot on the screen and a welldefined beam is critical to a high definition picture. The pathway of the laser beam can cause the beam to lose some of its propagation qualities, which in turn effect, the system efficiency. The optical efficiency of each optical surface goes down as a result of dust particles being bonded to the many optical. These dust particles cause a certain percentage of the laser light to scatter which could be as much as $3 \%$ or $4 \%$ per optical surface thus our prototype suffered a lot of loss due to dust particle contamination. The obvious point in building an optical train is to keep dust low and use few optical elements.

The optical design of the projection system starts with the combining of the three laser beams into a single beam through a set of dichroic mirrors. Once the beams have been combined they are focused on the polygon for horizontal scanning. The spinning polygon creates a horizontal - laser beam line which is then relayed to the galvo for vertical scanning. The relay of the modulated laser beam down collimates to the galvo. After the galvo the laser beam starts expanding and is then projected through a Nikon camera lens to the screen.

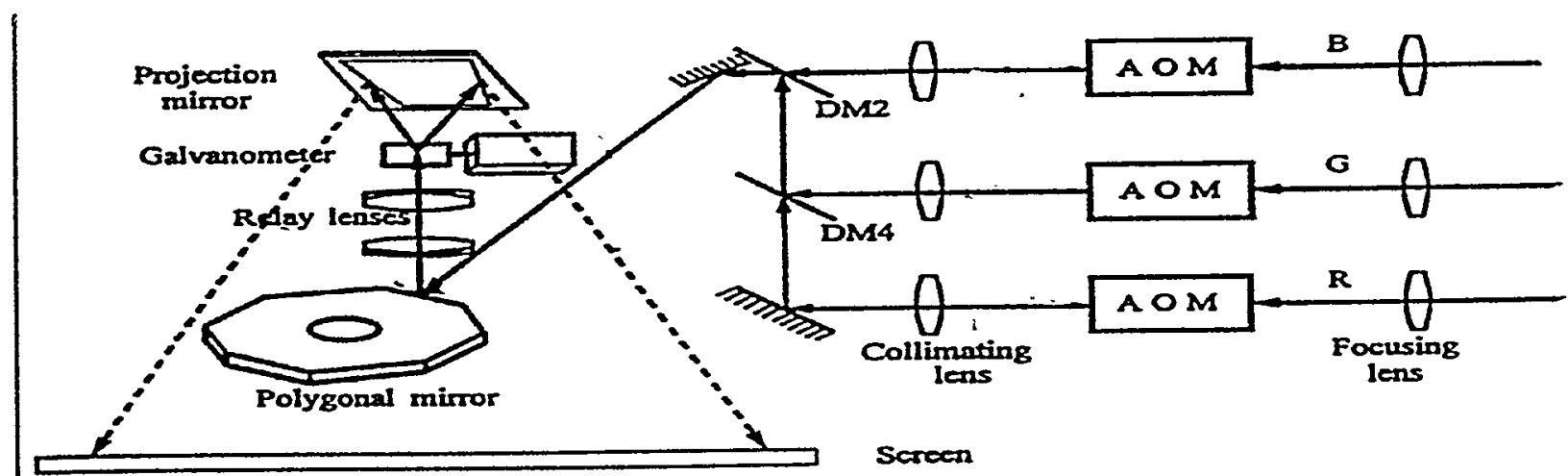

FIG. 7 Layout of the optical components 


\section{Polygon Scanner}

To provide horizontal scanning for the projector the best protocol seemed to be the spinning mirror. The design we decided on was a 52 -sided polygon mirror and a motor specification of $40,000 \mathrm{rpm}$. The conventional approach to polygon scanning has the laser beam focused at about 30 degrees incident to the polygon facet. The goal is to produce the largest scan angle from the polygon. Scan angle is important because it directly correlates to picture resolution. One of the tricks used to increase scan angle is to use facet tracking. Facet tracking is done in the AOM by the FM signal. The FM signal is synced to the horizontal scan rate. In the AOM the FM signal scans the laser beam to produce a scanning of the laser beam across the facet of the polygon. Even though this angle is very small it helps in the overall effect of producing a wider scan angle.

The use of the polygon scanner, for horizontal scanning of video information has a number of problems that we identified but did not solve. From our observation, these are several of the problems we have noted.

The timing of the video signal to the spinning of the polygon is critical, otherwise the waterfall effect will be observed. Waterfall is a horizontal line moving slowly up the picture. This horizontal line is an artifact because the first line of video is not always starting on the same facet of the polygon. Consequently there is this rolling line artifact. Solving this problem means having a start of facet detector, so the first line of video starts on the same facet all the time.

The problem of jitter and wobble are two other major areas that have to be dealt with. The jitter of the polygon creates a picture that moves up and down at a specific rate. Using optics to nullify the up and down motion of the polygon can solve the jitter problem. Picture wobble is a function of the motor controller speeding up and slowing down. To control wobble it is important that the controller senses very accurately, the speed of the polygon. When the speed is accurately controlled the picture will remain stable and not move side to side.

Because the polygon has a 52-sided mirrored surface the reflectivity is not equal for all the facets. So, a reflectivity correction table is needed to identify which facet has which percentage of reflectivity so that the light is averaged per line, thus giving a uniform look to the picture. 


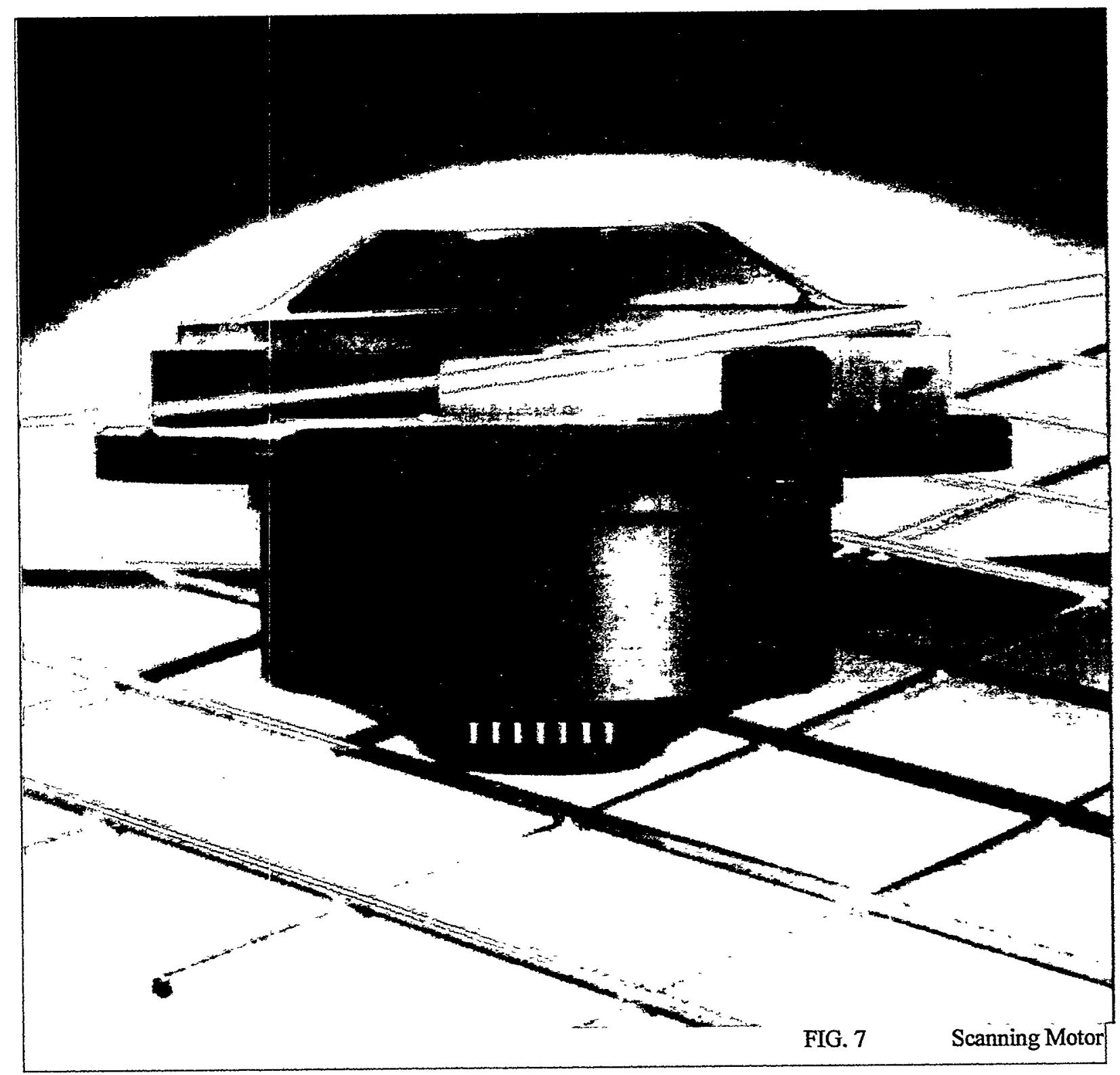

\section{Galvanometer Scanner}

Once the laser beam has been horizontally scanned it has to be down collimated so it can be vertically scanned. The vertical scanning completes the process for producing the video image. The most common approach to vertical scanning is with a galvanometer or galvo. One complete line of video horizontally scanned is focused on the mirror of the galvo. The galvo is moving at the vertical scan rate so each successive line of video is focused on to the galvo mirror and then reflected to the screen through some projection lens. The galvo functions without to many problems and the only error we noticed was some ringing effects at the top of the picture. Correction of this problem would mean better tuning the galvo drive circuit and or changing the shape of the drive signal. 


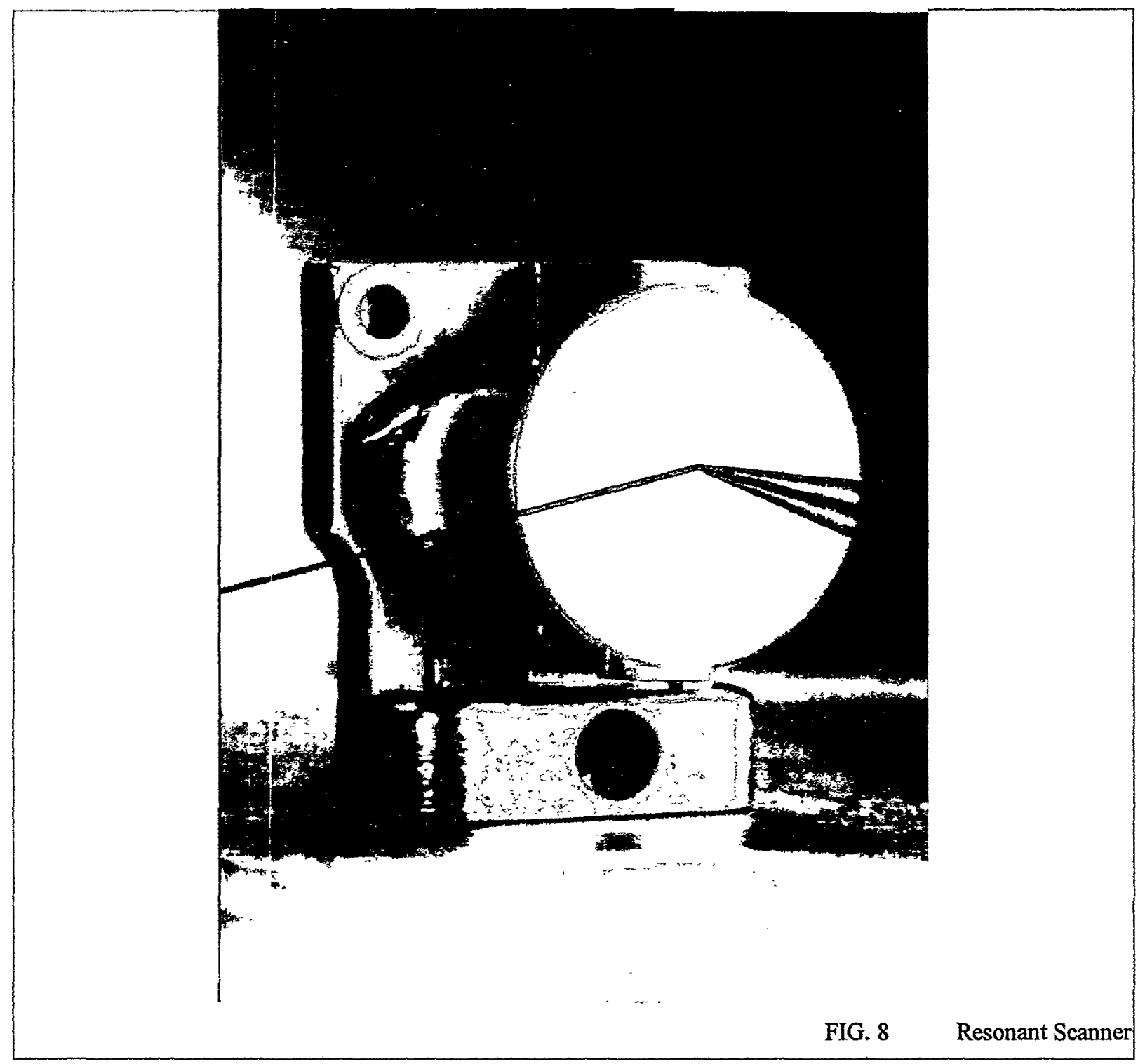

\section{Electronics}

The electronics for the prototype started first with the composite video and then separation into horizontal sync signal, vertical sync signal, and red, green, and blue video signals.

Once the signals are separated they have to be configured to drive the many parts of the projection system. The first element we worked with was the polygon drive electronics. The polygon needs to spin at the horizontal scan rate of $15750 \mathrm{kHz}$, so a TTL pulse at this rate was sent to the polygon's motor driver controller. Keeping the motor synced to the horizontal scan rate required a much more sophisticated controller than was supplied with the polygon. The original controller caused the picture to wobble side to side with no pattern of consistency, so a very stable motor controller is needed. The nature of the polygon motor requires a huge amount of current in its start up mode so, a very large linear power supply was needed. 
However once up to speed very little power was needed.

The vertical video signal drove a sawtooth wave generator, which in turn drove the galvo drive controller. Because the galvo is an oscillating mirror it's drive signal has to drive the motor in booth directions very quickly, but not so hard on the return trip of the mirror so as to cause ringing. The prototype had some ringing in the top of the picture. To stop the ringing in the picture a very carefully tuned sawtooth signal would be needed.

As already described the video signal is sent to the AOM's to modulate the laser beams. The AOM's needed two signals from the video board one for amplitude modulation and the other for facet tracking. The characteristic operation curves of the AOM's and the video signal are such that the electronics had to be designed so that the video signal would fall along the linear curve of the AOM. One other important item discovered was the fact that noise on the video signal would be modulated into the laser beam and seen on the screen.

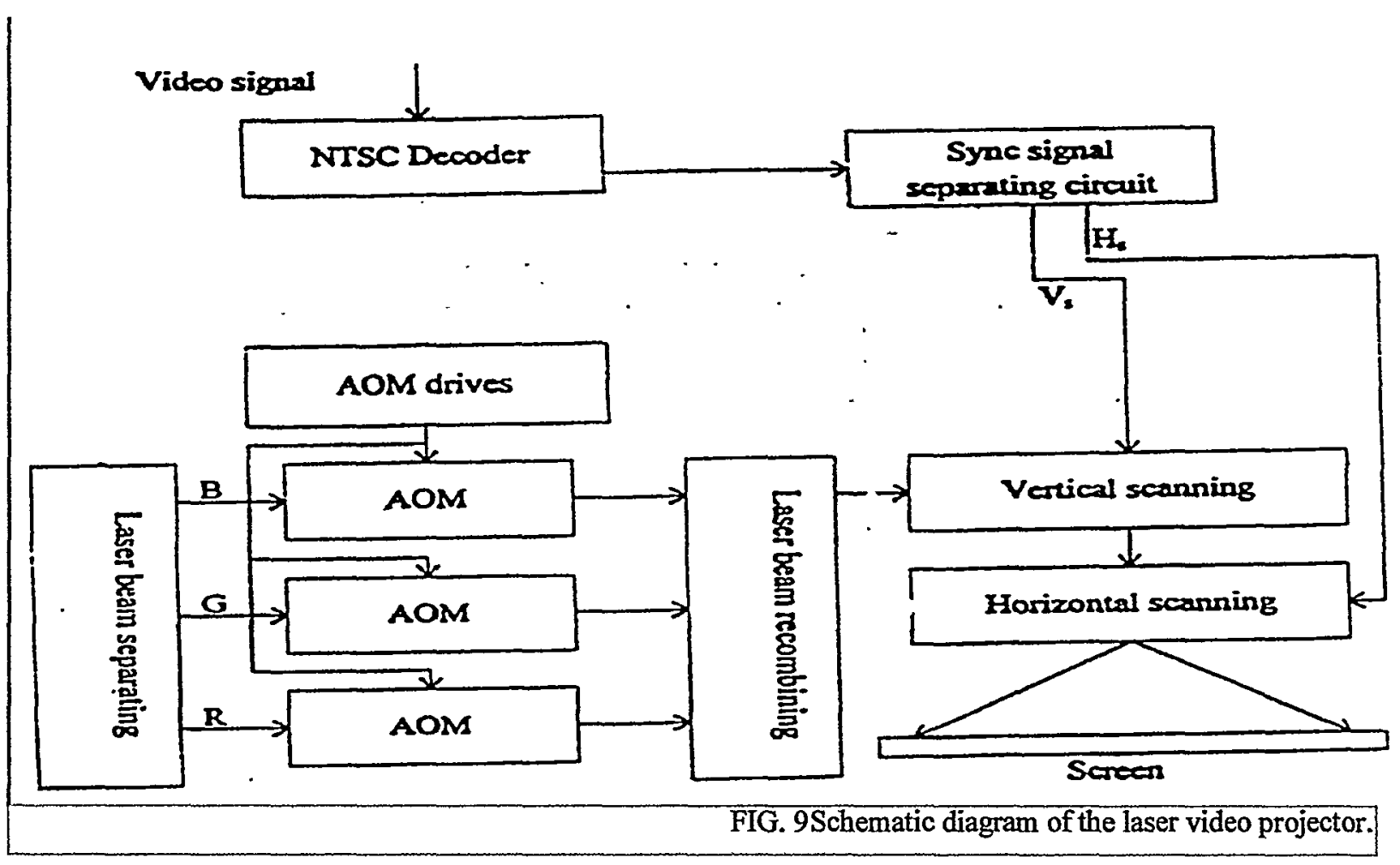

The electronics for our prototype required many power supplies to run the polygon, galvo, AOM drivers, video board, and lasers, for our prototype the total measured power consumed was less than 100 watts. 


\section{Conclusion}

The concept of using lasers for video display has been around since the days of the first lasers. Our experience concluded that it can be done, however many new technologies need to be invented and/or refined to make laser TV a reality.

\section{References}

1.Comparison of Colorimetries of Various Display Standards

2.MICROCHIP LASERS - a brief overview, October 1999

3.Advanced Solid State Lasers

\section{Photographs (Taken of the screen of Laser Television)}

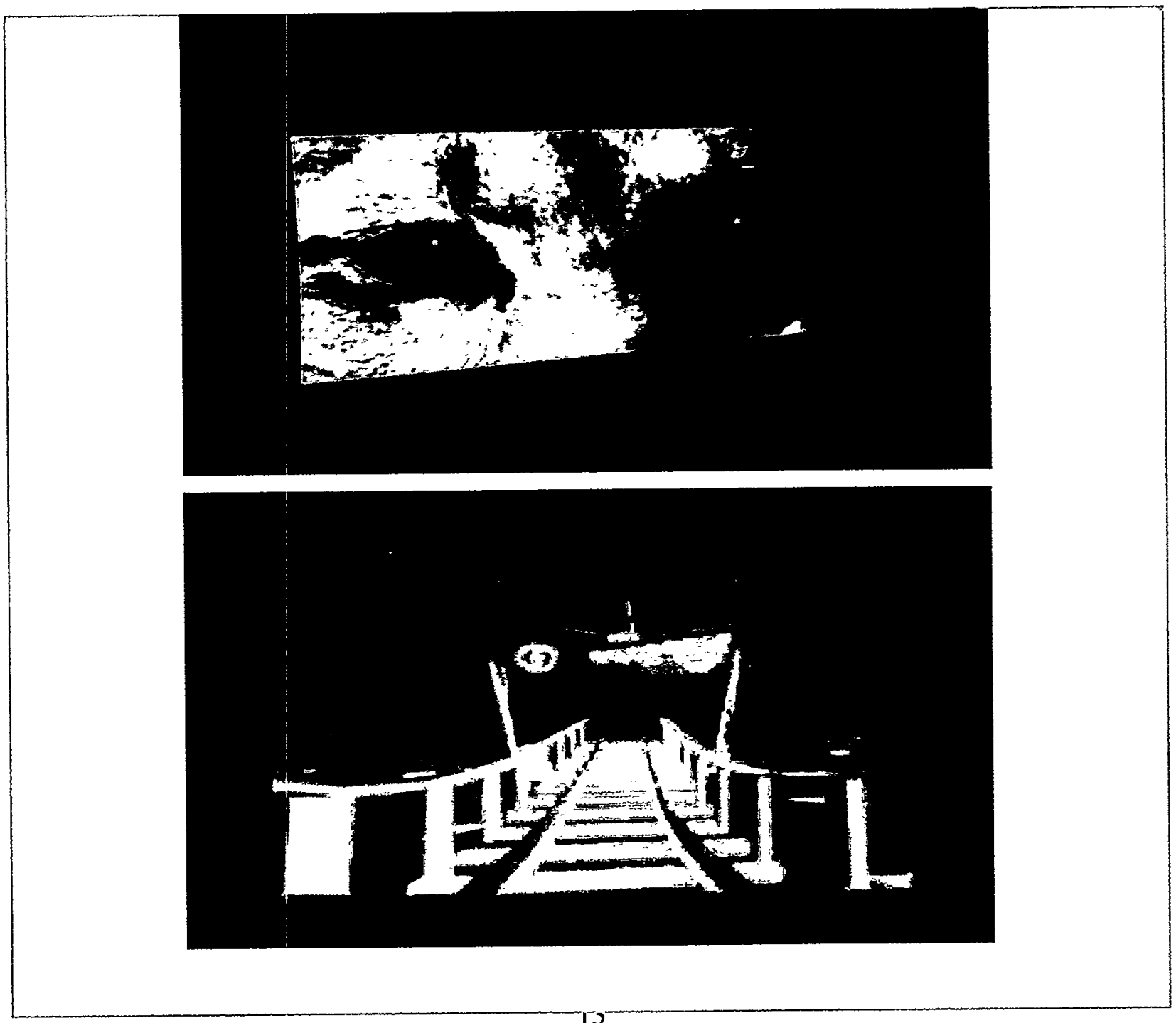




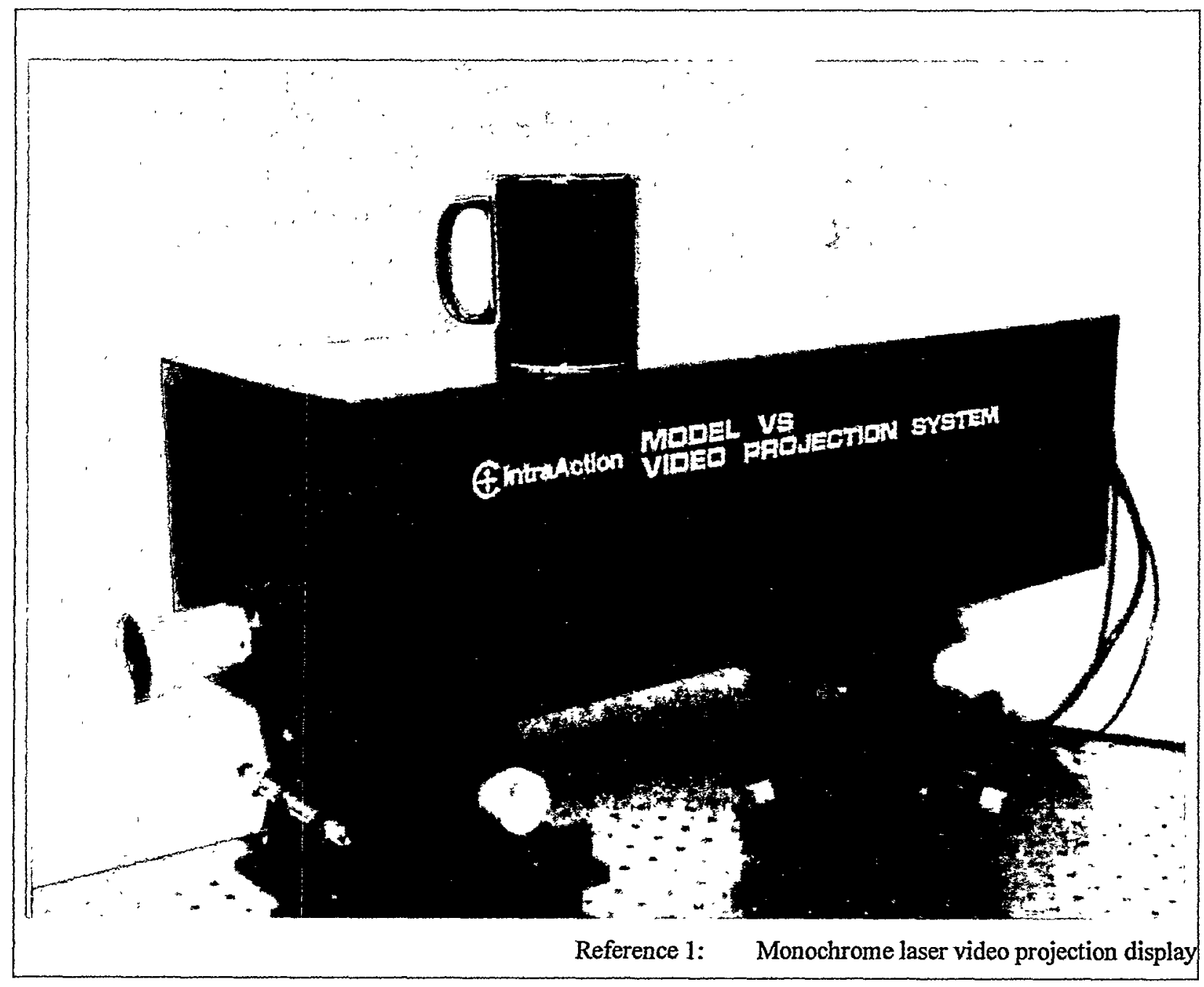

Comparison of Colorimetries of Various Display Standards

\author{
Philip S. Crosby \\ Atopics Autonomaus \\ for \\ Laser Vision Technologies \\ 24 Aug 1990
}

Inclosed is a chart showing the CIE $x$, $y$ diagram depicting a comparison of several colorimetries. With one slight exception, the LVT display gamut exceeds lhat of all other display standards with one trivial exeeption - the $x, y$ coordinates for the PAL blue phosphor lie slightly outside the LVT gamut. This is a very minor difference, and practically has no effect, since few actual CRTs have ever been able to achieve that coordinate due to contamination from tiny amounts of green and red phosphor residuc.

In practice, this means that any corrective matrix that might be used to adapt the LVT display to the colorimetry of the ineoming picture can be implemented with all positive coefficients; no polarity inversions are needed.

The $x$ and $y$ coordinates of the LVT display were based on the $R$, $G$, and $B$ wavelengths of 635,532 , and $473 \mathrm{nM}$, respectively. Further, it is assumed that the lasers can each be modulated to black ( $100 \%$ extinction).

The white points are indicated with D65 and C. Illuminant $C$ is used for the FCC standard, which is practically obsolete. D65 is the daylight $6500 \mathrm{~K}$ black body reference most commonly used for studio equipment. The white point and the three primary coordinates are all that are required to calculate a linear matrix for chromaticity transformations. 


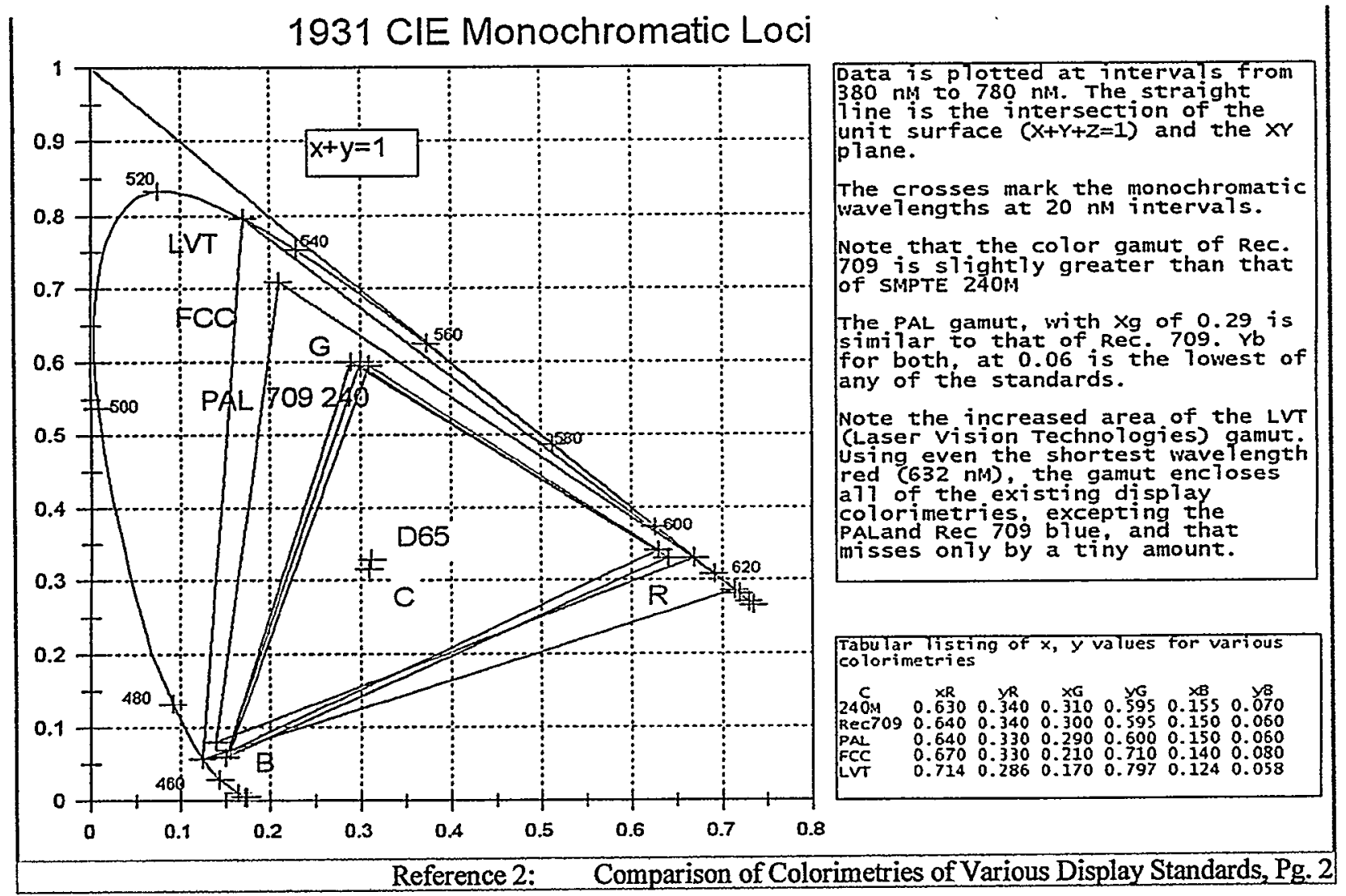


MICROCHIP LASERS - a brief overview, October 1999

Bruce Sinclair, University of St Andrews

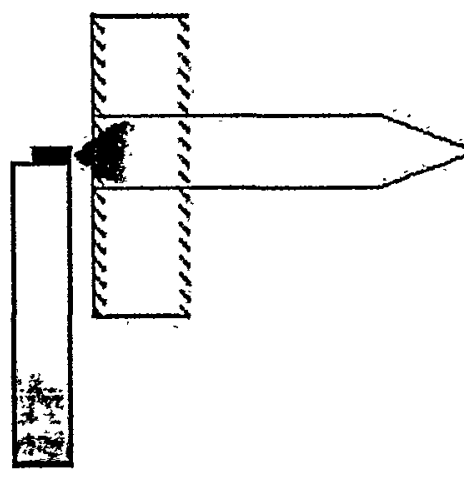

Microchip lasers are perhaps the ultimate in miniaturisation of diode-pumped solid-state lasers. A thin etalon of gain material (shown left in purple) has dielectric coatings applied to its plane surfaces, and a diode laser (shown black with red beam) provides a strongly localised pump source. The pump also produces thermal and gain related effects that provide cavity stability mechanisms, allowing the production of a high quality $\mathrm{TEM}_{00}$ beam. As first demonstrated a decade ago in Nd containing gain materials by Dixon and by Zayhowski and Mooradian, the short length of these devices allows the generation of single-frequency radiation in a readily mass produced laser. Scientists at Milan extended this concept into telecoms applications by using Er-Yb:glass as the gain material to generate tens of milliwatts of highpurity radiation at $1.5 \mu \mathrm{m}$.

The functionality of the microchip laser concept can be increased, while still maintaining its inherent simplicity and robustness, through the use of a "sandwich" of the gain etalon with another material. This additional material can take the form of a frequency-doubling crystal to shift the output of Nd devices into the visible, an electro-optic material to allow for frequency tuning, or a saturable absorber to permit passive Q-switching.

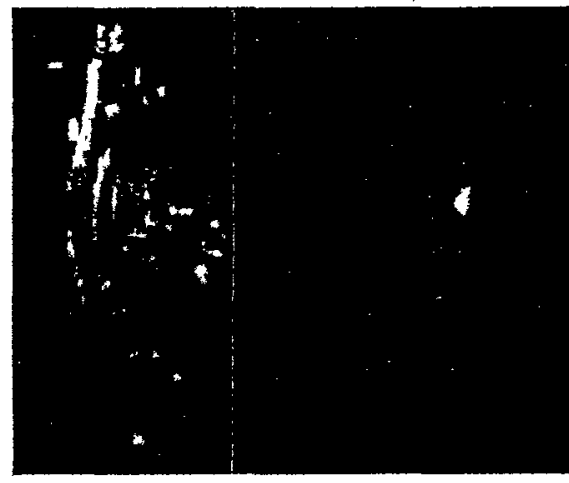

Work at St Andrews and at Hamburg has explored intracavity frequency-doubled Nd lasers and produced tens to hundreds of milliwatts of cw red, green, and blue light. The short cavities had low loss and a small beam waists. This allowed the generation of significant circulating $\mathbb{R}$ fields, and thus efficient second harmonic generation. The short cavity lengths also contributed to reduced intermodal coupling, and hence could remove the intensity instability known as "green noise". This type of technology was marketed by Uniphase, amongst others, as a replacement for air-cooled argon ion lasers in the reprographics and biomedical industries, for example.

Zayhowski at Lincoln Labs led the way in the development of passively Q-switched lasers. He sandwiches a slices of Nd;YAG with a slice of the saturable absorber Cr:YAG to produce cavities about $1 \mathrm{~mm}$ long. When pumped with one watt from a fibre-coupled diode these devices produce pulses as short as $218 \mathrm{ps}$, pulse energies as high as $14 \mu \mathrm{J}$, time-averaged powers of up to $120 \mathrm{~mW}$, 
with pulse repetition-rates between 8 and $15 \mathrm{kHz}$. He has also demonstrated quarter-millijoule output devices pumped with $10 \mathrm{~W}$ fibre-coupled diode laser arrays. The high peak powers and near-ideal speciral and spatial output of all these devices makes single-pass frequency conversion of their output rather efficient. One-watt pumped microchip lasers have produced $7 \mu \mathrm{J}$ of green and $1.5 \mu \mathrm{J}$ of $266 \mathrm{~nm}$ at pulse repetition rates around $10 \mathrm{kHz}$. These short pulses allow for compact LIDAR systems with 1 $\mathrm{mm}$ depth resolution, and the high intensities are useful for laser-induced breakdown spectroscopy. They have also been used to drive efficient optical parametric oscillators and amplifiers.

In Europe LETI-CEA with Nanolase have successfully developed passively Q-switched Nd:YAG lasers using a saturable absorber epitaxially grown on to the Nd: $Y A G$ gain material, though in some systems Nanolase utilise a conventional slice of Cr:YAG. These hight-specification and relatively low-cost lasers are marketed for applications in micro-fluorescence, ranging, and spectroscopy, amongst others. Devices operating at $1.55 \mu \mathrm{m}$ and $1.06 \mu \mathrm{m}$ have potential for use in collision avoidance systems in cars. Again the ability to generate harmonic wavelengths efficiently is important for many applications. Keller's gtoup in Zurich has taken passive Q-switching to a new recörd, producing 37 ps pulses at $1,06 \mu \mathrm{m}$ using a semiconductor saturable absorber, and have also used their SESAM technology at telecom wavelengths.

There remains much interest in the physics of microchip lasers, both in terms of how they work, and in their use for experiments in quantum optics.

Microchip lasers have found their own distinctive role. Their robust and readily mass-produced structures are very attractive. Couple this with their single-frequency cw performance, or their excellence at generating sub-nanosecond pulses, and one sees that they are well suited for many applications.

Zayhowski at Lincoln Labs led the way in the development of passively Q-switched lasers. He sandwiches a slices of Nd:YAG with a slice of the saturable absorber Cr:YAG to produce cavities about $1 \mathrm{~mm}$ long. When pumped with one watt from a fibre-coupled diode these devices produce pulses as short as $218 \mathrm{ps}$, pulse energies as high as $14 \mu \mathrm{J}$, time-averaged powvers of up to $120 \mathrm{~mW}$, 


\title{
A Diode Array Pumped Continuous Wave Blue Microchip Laser
}

\author{
David G. Matthews 1 , Neil MacKinnon", \\ Richard S. Conroy ${ }^{1}$ and Bruce D. Sinclair ${ }^{3}$ \\ 1J. F. Allen Physics Research Laboratories, School of Physics and Astronomy, \\ University of St. Andrews, St. Andrews, Fife, KY169SS, Scotland, U.K.
}

${ }^{2}$ I E Optomech Ltd, Crabtree Farm, Newnham, Northants, NN113ET, England, U.K.

\begin{abstract}
A diode pumped Nd:YAGIKNbO 3 composite material microchip laser has generated up to $33 \mathrm{~mW}$ of blue $(473 \mathrm{~nm}) \mathrm{cw}$ radiation near room temperature. The fundamental radiation generated by the $946 \mathrm{~nm}$ transition in Nd:YAG was frequency doubled in $\mathrm{KNbO}_{3}$ angle cut to be type I critically phase-matched at $40^{\circ} \mathrm{C}$.
\end{abstract}

Rare earth and transition metal solid state lasers, Visible lasers, Nonlinear optics - devices

\section{Introduction}

Compact all-solid state blue and green lasers are desired as replacements for low power $\mathrm{cw}$ Argon ion lasers. Arguably the solid-state laser technology offering the ultimate in minaturisation and potential for low cost mass-production is the microchip format. Our group recently reported $130 \mathrm{~mW}$ of green generated in a composite-material microchip device [1,2].

Although the blue diode laser is expected to become important, at present short operational lifetimes limit their commercial use. The diode-pumped microchip laser format is likely to be the most compact of the non-blue-diade options.

Significant power levels of $9 \mathrm{~mW}$ and $15 \mathrm{~mW}$ have been reported from Ti:Sapphire laser pumped $\mathrm{Nd}: \mathrm{YAG} / \mathrm{KNbO}$ and $\mathrm{Nd}: \mathrm{YAlO}_{3} / \mathrm{KNbO}_{3}$ microchip lasers respectively $[3,4]$.

Our group recently reported $1 \mathrm{~mW}$ of $\mathrm{cw}$ blue (473nm) generated from a 2 Watt diode array pumped $\mathrm{Nd}: \mathrm{YAG} / \mathrm{KNbO}_{3}$ mictochip device $[3,5]$. We report here $33 \mathrm{~mW}$ and $5 \mathrm{~mW}$ of blue radiation from a similar device utilising the lower power 1.2 Watt and 0.5 Watt diodes respectively.

\section{Experimental Configuration}

The composite material microchip laser consisted of a $1.5 \mathrm{~mm}$ thick $1.1 \%$ Nd:YAG crystal polished planeparallel and bonded to a nominally $1.5 \mathrm{~mm}$ thick planeparallel $\mathrm{KaNbO}_{3}$ crystal angle cut for type I critical phase matching of $946 \mathrm{~nm}$ radiation at $T_{p \mathrm{pm}}=40^{\circ} \mathrm{C}$. The crystal set was coated for high reflectance at 946 $\mathrm{nm}$ and high transmittance at $1064 \mathrm{~nm}, 1320 \mathrm{~nm}$ and $473 \mathrm{~nm}$, whilst measurements indicated a reflectance of $24 \%$ at $810 \mathrm{~nm}$. A stable cavity is formed by the pumped surface deformation and thermal lensing induced by the absorption of the pump radiation[6].

The threshold for the quasi-three level ${ }^{4} \mathrm{~F}_{3 / 2}-{ }^{4} \mathrm{I}_{92}$ Nd transition is reduced by the higher lying $Z_{5}$ stark level $\left(848 \mathrm{~cm}^{-1}\right)$ in the ${ }^{4} I_{92}$-manifold in YAG compared to that for Nd:YVO, $\left(439 \mathrm{~cm}^{-1}\right)$. However the low absorption coefficient of $1.1 \%$ Nd:YAG $\left(0.85 \mathrm{~mm}^{-1}\right)$ at $810 \mathrm{~nm}$ compared to $3 \% \mathrm{Nd}: \mathrm{YVO}_{4}\left(12 \mathrm{~mm}^{-1}\right)$ makes YAG less desirable as a microchip medium. More significantly as Nạ:YAG is isotropic it was expected that in order to generate efficiently the $946 \mathrm{~nm}$ fundamental in the correct polarisation for second harmonic generation would require insertion of a polariser. Potassium Niobate $\left(\mathrm{KNbO}_{3}\right)$ was selected as the doubling material due to its high nonlinearity (dest $=13 \mathrm{pm} / \mathrm{V}$ ) and an ability to be birefringently phasematched for second harmonic generation of the $946 \mathrm{~nm}$ fundamental.

The $1.02^{\circ}$ walkoff between the fundamental and second harmonic introduced by the $1.5 \mathrm{~mm}$ long $\mathrm{KNbO}_{3}$ was calculated to have reduced the conversion efficiency by only $23 \%$.

Reference 4: Advanced Solid State Lasers, Pg.1 
The difference in the crystal set used in the present experiments and those used in previous work [5] was a $5^{\circ} \mathrm{C}$ lower phase-matching temperature which produced maginally higher $946 \mathrm{~nm}$ powers due to the lower thermal population of the lower laser level. More significantly no depoling was observed in the $\mathrm{KNbO}_{3}$ and the crystal set exhibited generally good optical quality.

As a result, lower threshold pump powers were obtained, so lower power diodes could be used. In general it is observed that higher brightness diodes with emitter widths of less than or equal to $100 \mu \mathrm{m}$ produce optimum performance in microchip lasers.

In initial experiments a $0.5 \cdot \mathrm{W}(50 \mu \mathrm{m} \times 1 \mu \mathrm{m}$ emitter) diode lasér array and $\mathrm{a} f=8 \mathrm{~mm} / \mathrm{f}=6.5 \mathrm{~mm}$ lens pair were used to focus the $\lambda p=808.5 \mathrm{~nm}$ pump beam into the crystal set producing a maximum incident power of $\mathrm{P}_{\text {inc }}=455 \mathrm{~mW}$.

In a second series of experiments a $1.2 \mathrm{~W}(100 \mu \mathrm{m}$ $x 1 \mu \mathrm{m}$ emitter) diode laser and a $f=6.5 \mathrm{~mm}$ aspheric If $=8 \mathrm{~mm}$ lens pair were used generating a maximum incident power of $P_{\text {ixc }}=1.1 \mathrm{~W}$.

In both cases over $24 \%$ of the pump was reflected from the crystal surface. Although this was an improvement over previous crystal sets (28\%) this still represents a major loss of useful pump power. Of the non-reflected incident light $66 \%$ was absorbed in the Nd:YAG crystal.

The Nd:YAG/ $/ \mathrm{KNbO}_{3}$ crystal set was mounted on a thermoelectric cooler assembly, as shown in figure 1 , which allowed temperature control. At a given incident pump power it was necessary to adjust the thermoelectric cooler power to maintain the crystal at the optimum phase matching temperature of $40^{\circ} \mathrm{C}$. Due to the thermal gradient between the chipset and heat sink the reference heat sink temperature $T_{x}$ producing optimum phase matching varied with laser pump power.

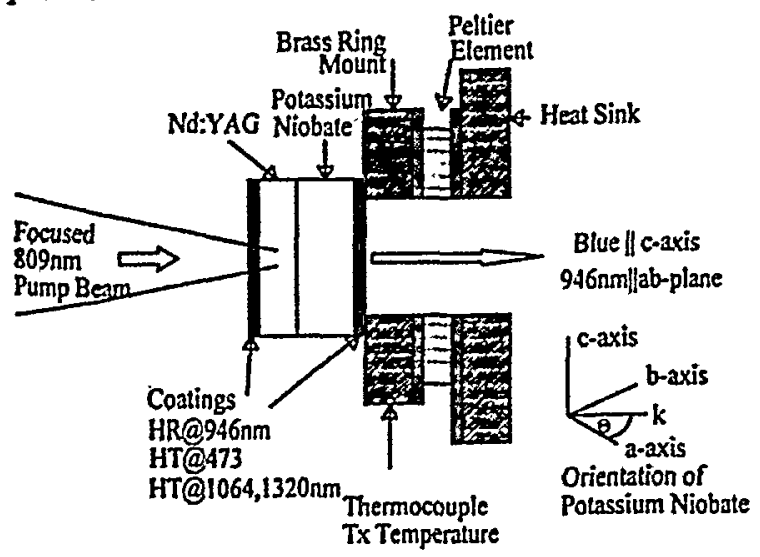

Results and Discussion

0.5W Diode- pumped Results

Temperature Bandwidth. Using a $0.5 \mathrm{~W}$ diode, the crystal heat sink temperature $\mathrm{T}_{\mathrm{x}}$ which maximised the blue output power, at full pump power, was $38.9^{\circ} \mathrm{C}$. The short non-linear crystal length resulted in an acceptably broad temperature bandwidth of $2.2^{\circ} \mathrm{C}$ FWHM, as shown in figure 2.

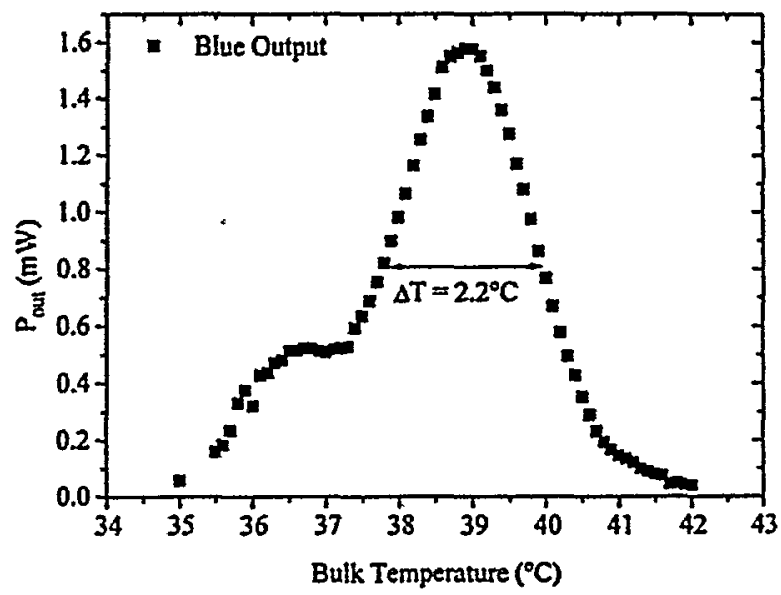

Figure 2. Phase matching Temperature Bandwidth using a $0.5 \mathrm{~W}$ laser diode pump.

Laser Output Power. At full incident pump power $P_{i x c}=$ $455 \mathrm{~mW}\left(\mathrm{P}_{\mathrm{abs}}=230 \mathrm{~mW}\right)$ the $0.5 \mathrm{~W}$ diode generated a maximum blue output power of $\mathrm{P}_{\mathrm{blu}}=5.1 \mathrm{~mW}$ in one direction, as shown in figure 3 , with a threshold of $P_{\text {ine }}$ $=206 \mathrm{~mW}$. A similar amount of blue power will have been generated in the opposite direction. No attempt was made to return this light into the desired direction. As the incident pump powier was reduced the crystal heat sink temperature $T_{x}$ was adjusted to maintain optimum phase matching and therefore maximum blue output power. The change in slope efficiency above $400 \mathrm{~mW}$ was due to difficulties in optimising the crystal temperature.

The blue power will depend on the mode volume as well as the power of the infrared beam. Which will cause a deviation from the otherwise expected squared dependence of blue power on $\mathbb{R}$ power. Degradation of phase matching due to a temperature profile across the $\mathrm{KNbO}_{3}$ was not a problem.

Figure 1. Schematic of Diode-pumped Microchip Laser 


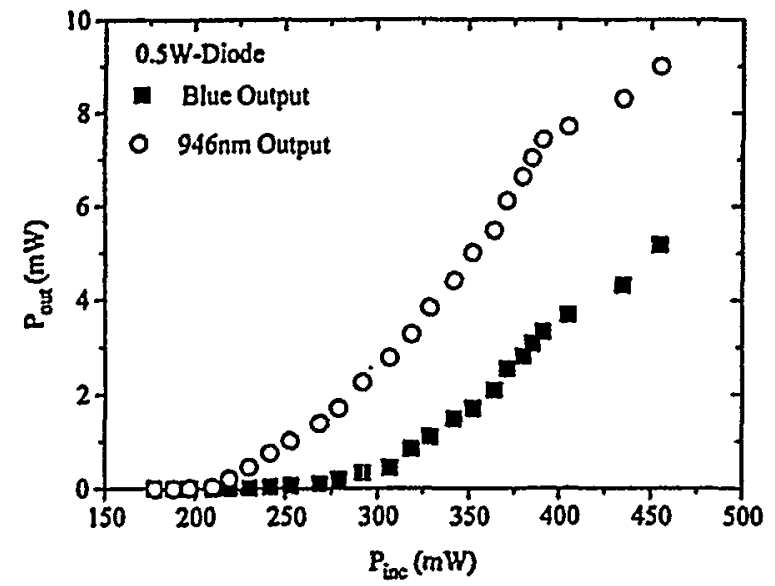

Figure 3. $0.5 \mathrm{~W}$ Diode-pumped: Blue and $946 \mathrm{~nm}$ laser output power as a function of the total incident pump power.

Beam Quality. The $946 \mathrm{~nm}$ and blue output beams were TEM ${ }_{\infty 0}$ with mode sizes of $\omega_{0} \approx 105 \mu \mathrm{m}$ and $75 \mu \mathrm{m}$ respectively. In both cases the ellipticity of the beam was less than 1:1.1.

At maximum pump power and optimum heat sink temperature $\left(T_{x}=38.9^{\circ} \mathrm{C}\right)$ over $9 \mathrm{~mW}$ of infrared was produced. Three axial modes centred at $946.4 \mathrm{~nm}$ with a mode spacing of $0.2 \mathrm{~nm}$ were present. The calculated longitudinal $946 \mathrm{~nm}$ mode spacing for this cavity was $0.1 \mathrm{~mm}$, suggesting that adjacent modes are prevented from oscillating due to spatial hole burning.

\subsection{Watt Diode-pumped Results}

Temperature Bandwidth. The phase matching temperature bandwidth of the $\mathrm{KNbO}_{3}$ crystal using the $1.2 \mathrm{~W}$ diode showed the same form as with the $0.5 \mathrm{~W}$ laser as shown in figure 2. As expected, the higher incident pump powers required less additional heating of the crystal set from the thermoelectric element such that the optimum heat sink temperature was $T_{x}=$ $32.3^{\circ} \mathrm{C}$ at full power.

Laser Output Power. At full incident power $P_{\text {inc }}=1.1$ $\mathrm{W}\left(\mathrm{P}_{\mathrm{aba}}=550 \mathrm{~mW}\right)$ the $1.2 \mathrm{~W}$ diode generated a maximum blue output power of $P_{\text {bluc }}=33 \mathrm{~mW}$, as shown in figure 4 , with a threshold of $P_{\text {inc }}=330 \mathrm{~mW}$. Again, as the incident pump power was reduced, the supplementary heat from the thermoelectric element was adjusted to obtain the optimum phase matching temperature and therefore maximum blue output power.

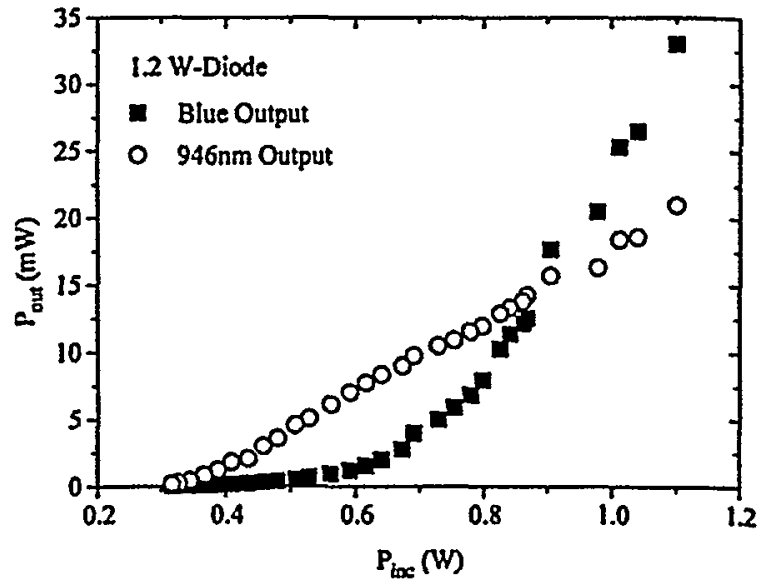

Figure 4. $12 \mathrm{~W}$ Diode pumped: Blue and $946 \mathrm{~mm}$ laser output power as a function of incident pump power $P_{\text {ince. }}$

Polarisation. In previous work $[3,5]$ it was observed that, despite the isotropic nature of the Nd:YAG crystal, the infrared output was always polarised parallel to the $\mathrm{KNbO}_{3}$ ab-plane $\left(\mathbb{R}_{0}\right)$ and thus orthogonal to the blue output which was polarised parallel to the c-axis. No evidence of a $946 \mathrm{~nm}$ component $\left(\mathbb{R}_{x_{0}}\right)$ perpendicular to the ab-plane was detected. However the level of damage to the crystal set, induced in the manufacturing process, meant that only a very small area of the crystal set produced laser action. In the present experiments, using a good quality crystal set, the polarisation of the infrared varies depending on where the crystal is being pumped. In general, the blue output power is maximised when the infrared component $\mathbb{I R}_{0}$ (which has a polarisation orthogonal to the blue) is maximised. The $\mathbb{R}_{s o}$ component does not lead to blue generation and as such acts as a parasitic loss mechanism for the total intracavity infrared power.

In the crystal set used in these experiments the whole aperature was free of obvious optical damage. However, both the total infrared power and the ratio of the $\mathbb{I R}_{90}$ to $\mathbb{I R}_{0}$ polarisation components varied across the crystal as shown in figure 5 and 6.

The highest blue output powers were accompanied with the highest $\mathbb{I}_{0}$ and the lowest $\mathbb{I}_{p_{0}}$ powers. Spatially two lines across the surface of the crystal were identified which produced the highest blue powers. 


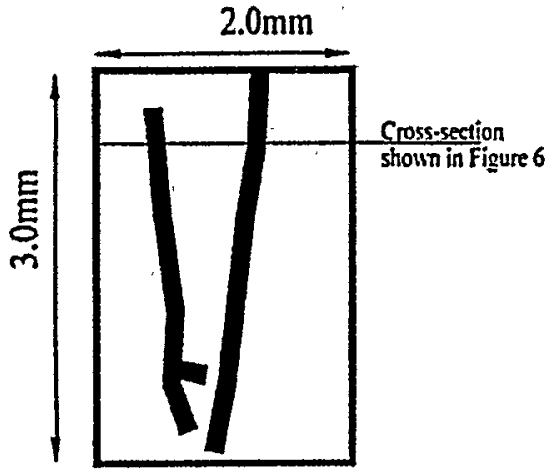

Figure 5: Regions of maximum blue output $(>15 \mathrm{~mW})$ within the $3 \times 2 \mathrm{~mm}$ crystal set are shown shaded.

A possible explanation is that areas adjacent to these lines experience appropriate levels of birefringence or anisotropic gain enhancing the $\mathbb{R}_{0}$ component. A cross-sectional scan of the crystal shows the variation of the infrared polarisation components and the blue power levels, figure 6 , where the regions near $x=0.75 \mathrm{~mm}$ and $1.25 \mathrm{~mm}$ from left of crystal show a strong preference for the $\mathbb{R}_{0}$ polarisation component and higher blue output powers.

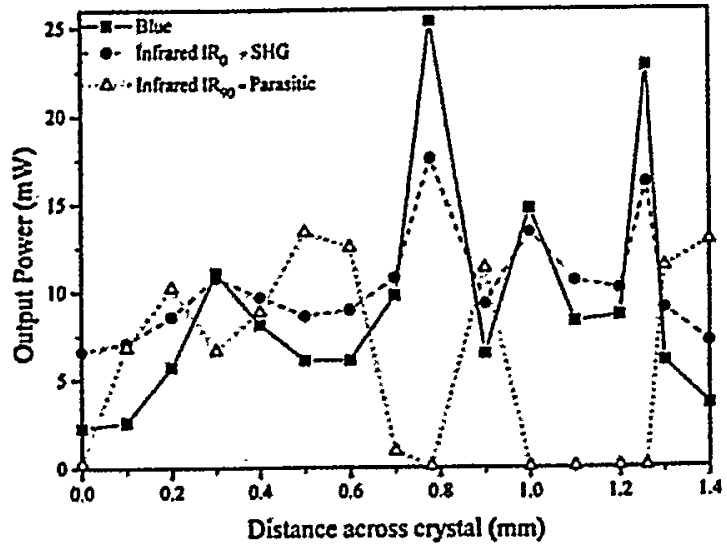

Figure 6. Polarisation cross-section ( Figure 5) of Infrared and Blue across the crystal set.

An examination of the temporal development of the blue and infrared polarisation components showed that the preferential polarisation at the optimum position was not formed in conjunction with cavity formation. Therefore the $\mathbb{I}_{90}$ component is approximately an order of magnitude lower than $\mathbb{I}_{0}$ even directly after switch on as shown in figure 7.

The heat sink temperature was set to $T_{x}=32.5^{\circ} \mathrm{C}$ which produced Immediately after switch on the abscence of absorbed pump power heating means that the $\mathrm{KNbO}_{3}$ temperature is less than that required for optimum phase-matching $T_{p m}=40^{\circ} \mathrm{C}$. As the pump power is absorbed the cavity is formed (less than 1 second) and the crystal is heated towards the phasematching temperature $T_{p m}$. This decreases the total infrared output due to an increase in the population level of the lower laser level from the ground state but mainly due to the conversion of infrared photons to the blue. In figure 7 the blue output decreases after 6 seconds, however after approximately one minute this increases steadily requiring approximately 5-10 minutes to stabilise. It was apparent that at each incident pump power the determination of the optimum heat sink temperature $T_{\mathbf{x}}$. which produced optimum phase-matching was a time consuming process.

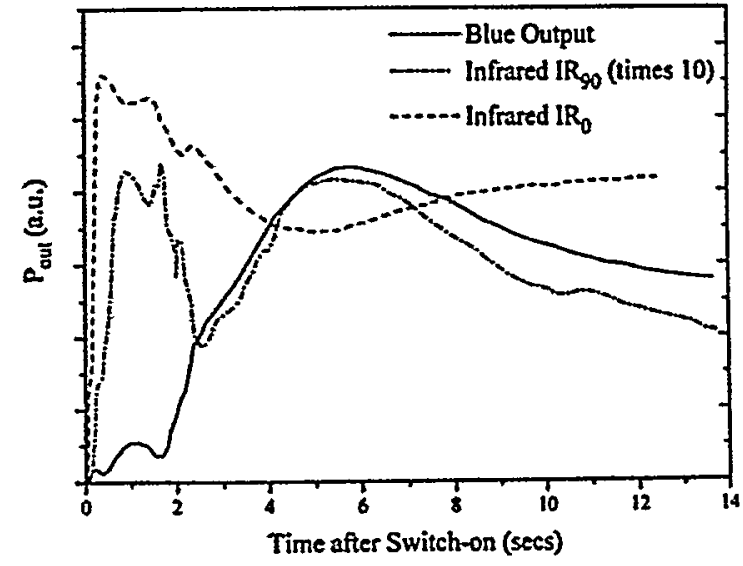

Figure 7. Infrared and Blue output powers after laser switch on.

Beam Quality. An analysis of the beam divergence indicated that the $946 \mathrm{~nm}$ and blue output beams were TEM ${ }_{\infty 0}$ with mode sizes of $\omega_{0} \approx 110 \mu \mathrm{m}$ and $75 \mu \mathrm{m}$ respectively with no significant ellipticity. This result shows the advantage of using the $1.2 \mathrm{~W}$ high brightness diode which produces excellent beam quality despite the $100 \mu \mathrm{m}$ emitter width. As was reported in a previous paper the $2 \mathrm{~W}$ diode with a $200 \mu \mathrm{m}$ emitter produced a highly elliptical output beam consistent with TEM ${ }_{00}$ and TEM $M_{10}$ modes. This is consistent with the focused pump beam being larger than the emitter width and in the case of the $2 \mathrm{~W}$ diode larger than the laser mode waist diameter $2 \omega_{\mathrm{o}}$.

At optimum blue generation over $22 \mathrm{~mW}$ of infrared output power was generated. The polarisation of the infrared was over $90 \%$ parallel to the ab-plane $\left(\mathbb{R}_{0}\right)$. Three axial modes centred at $946.4 \mathrm{~nm}$ with a mode spacing of $0.2 \mathrm{~nm}$ were present. An examination of the orthogonal infrared polarisation components showed no observable difference in the mode structure. 
Noiss. Intensity fluctuations due to mode coupling in green microchip lasers, 'green noise', have been reported $[1,2,7]$. In the blue microchip laser "Blue noise' was present producing intensity fluctuations the depth and spectral content of which varied with crystal temperature. A RF spectnum analysis indicated both distinct frequency and random noise are present dependent on the operating conditions. Under optimum operating conditions, which in this case produced $24 \mathrm{~mW}$ of blue, the intensity fluctuations were typically up to $\pm 50 \%$ as shown in figure 8 .

In contrast with the analogous green microchip laser no operational parameters were found which resulted in "quiet' operation.

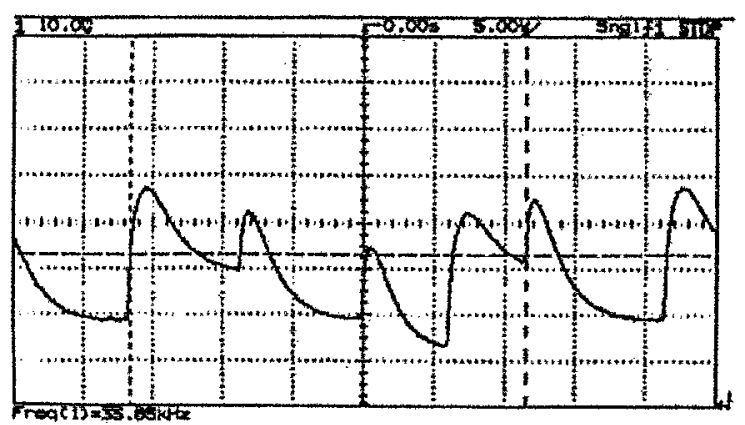

Figure 8. Blue Intensity Fluctuations: Time Scale ${ }_{\mu} \mu \mathrm{s} / \mathrm{div}$

\section{Conclusion}

A diode pumped composite material blue microchip lasers based on Nd:YAG and $\mathrm{KNbO}_{3}$ produced $\mathrm{cW} 473$ $\mathrm{nm}$ output powiers in excess of $30 \mathrm{~mW}$. The optimum pump region within the crystal set was that which produced significant polarisation of the fundamental parallel to the ab-plane of the $\mathrm{KNbO}_{3}$. At present it is unclear if these 'anisotropic' regions are produced by induced stress within the Nd:YAG.

Investigations are in progress to clarify the mechanisms leading to the polarisation eigenmodes observed and means by which the substantial blue noise may be eliminated.

\section{Acknowledgments}

We acknowledge the support of the UK EPSRC (grant GR/K14766). The subject matter and results reported here are subject to pending UK and international patent applications.

\section{References}

1. N. MacKinnon and B. D. Sinclair, Opt. Commun. 105, 183 (1994).

2. N. Mackinnon and B. D. Sinclair, in Conference on Lasers and Electro-Optics, Vol. 8 of 1994 OSA Technical Digest Series (Optical Society of America, Washington D.C., 1994), paper CTuP2.

3. D. G. Matthews, R. S. Conroy, B. D. Sinclair and N. MacKinnon, Opt. Lett, 21, 198 (1996).

4. J. H. Zarrabi, P. Gavrilovic and S. Singh, Appl. Phys. Lett, 67, 2439 (1995).

5. D. G. Matthews, R. S. Conroy, N. Mackinnon and B. D. Sinclair, Conference on Quantum Electronics QE-12, (Institute of Physics, Southhampton, U.K. September 1995).

6. J. J. Zayhowski, Lincoin Laboratory Journal, 3, 428 (1990).

7. T. Baer, J. Opt. Soc. Am. B 3, 1175 (1986). 